\title{
Power Reserves Control for PV Systems with Real-Time MPP Estimation via Curve Fitting
}

\author{
Efstratios I. Batzelis, Member, IEEE, Georgios E. Kampitsis, Member, IEEE, Stavros A. \\ Papathanassiou, Senior Member, IEEE
}

\begin{abstract}
In order for a PV system to provide a full range of ancillary services to the gird, including frequency response, it has to maintain active power reserves. In this paper, a new control scheme for the dc/dc converter of a two-stage PV system is introduced, which permits operation at a reduced power level, estimating the available power (maximum power point - MPP) at the same time. This control scheme is capable of regulating the output power to any given reference, from near-zero to $100 \%$ of the available power. The proposed MPP estimation algorithm applies curve fitting on voltage and current measurements obtained during operation to determine the MPP in real time. This is the first method in the literature to use the non-simplified singlediode model for the determination of the MPP and the five model parameters while operating at a curtailed power level. The developed estimation technique exhibits very good accuracy and robustness in presence of noise and rapidly changing environmental conditions. The effectiveness of the control scheme is validated through simulation and experimental tests using a 2 kW PV array and a dc/dc converter prototype at constant and varying irradiance conditions.
\end{abstract}

Index Terms - Active power control, curve fitting, linearized converter model, maximum power point tracking (MPPT), photovoltaic (PV), power reserves, single-diode model.

\section{INTRODUCTION}

$\mathrm{N}^{\prime}$ ETWORK codes impose increasing ancillary service requirements to distributed generation, including renewable energy plants [1], [2], which are gradually extending to the provision of frequency response. In order for a PV system to provide such services, it needs to maintain active power reserves and perform up/down regulation of its output power in response to commands issued by the system operator [3]-[7].

In principle, two methods exist to implement power reserve capabilities in a PV system: either installing energy storage, at increased system cost and complexity, or employing a power curtailment technique [4], [8]. The latter approach is readily realized modifying the maximum power point tracking (MPPT) algorithm to operate at a suboptimal power level, rather than at the MPP [3]-[7], [9]-[13]. This is the focus of this paper.

In single-stage inverters, power reserves capability is achieved by enhancing the inverter control [10]-[13]. On the other hand, in two-stage systems as addressed in this paper, the dc/dc converter control has to be modified instead [3]-[6], [9], which is a more challenging task [4]. In [9], a typical

Manuscript received June 23, 2016; revised October 4, 2016 and January 4, 2017; accepted February 18, 2017.

The authors are with the School of Electrical and Computer Engineering National Technical University of Athens, Athens 15780, Greece (e-mail: stratis.batzelis@gmail.com; gkampit@gmail.com; st@power.ece.ntua.gr).
Incremental Conductance (INC) MPPT algorithm is adopted and properly enhanced, offering simple implementation, yet limited dynamic response properties. In [3]-[6], improved dynamic response and controllability are achieved employing PI regulators. However, since the $P-V$ curve is non-monotonic, a simple PI controller regulating the output power is not effective. For this reason, the PI controller employed in [3]-[5] regulates the operating voltage, rather than the power, which in turn does not permit accurate tracking of a specific power reference command. In [6], this problem is partially overcome by changing the sign of the error input of the PI power controller, which may still lead to undesirable operation on the left-hand side of the $P-V$ curve [7], [10], [14].

Furthermore, an important consideration for a power reserves control scheme is whether the MPP can be estimated while operating at a curtailed output. This is necessary for the PV station in order to provide a given amount of reserves, either in terms of absolute power (kW/MW) or as a fraction of available maximum power (reserve ratio). References [3]-[7], [10], [12] implement techniques that follow external power commands, in addition to frequency response, employing different MPP estimation methods. In [12] and [7], irradiance and temperature measurements are utilized to extrapolate datasheet information to the actual conditions, whereas in [3]-[6], [10] a mathematical model is applied to voltage and current measurements acquired by the $\mathrm{dc} / \mathrm{dc}$ converter sensors. The former approach is simpler, but compromised by the inevitable deviations of actual PV modules characteristics from datasheet values, as well as by the translation formulae employed. In [3]-[6], [10], adaptation to the actual system characteristics is achieved, but the circuit models employed are oversimplified or do not present sufficient immunity to noise. In particular, [3], [4] and [10] apply linearquadratic or quadratic models to only two or three previous measurement samples. To improve robustness in noisy environments, a quadratic curve fitting approach is proposed in [5] and further improved in [6], employing a simplified version of the single-diode PV model.

In order to address the aforementioned limitations, a new power reserves control scheme for the dc/dc converter of a twostage PV system is introduced in this paper. Its novelty lies in the fact that a single PI controller is applied to regulate power, rather than voltage, permitting operation at a specific power reference provided by an external command. This is not possible with voltage regulators adopted in other works. The operating point of the PV generator is kept always in the preferable right-hand side of the $P-V$ characteristic, allowing for operation at any power reference, from near-zero to $100 \%$ of 
the available maximum power. The proposed scheme employs also a ripple control method to regulate the power fluctuation to the appropriate levels.

Furthermore, a new method to estimate the MPP in real time, while operating at a reduced power level, is introduced. The proposed algorithm is based on the fundamental non-simplified single-diode PV model and applies least squares (LSQ) curve fitting to a large set of voltage and current samples. The method not only estimates the MPP voltage and power, but it actually determines the five model parameters and hence the entire $P-V$ characteristic in real time. The curve fitting employed provides good accuracy and robustness in presence of noise, as well as under rapidly changing irradiance conditions. The MPP estimator relies on the standard voltage and current sensors of the dc/dc converter, requiring no additional equipment, like irradiance or temperature sensors. This is the first method in the literature to estimate the MPP and the model parameters when the system operates at a suboptimal power level (away from the MPP), benefiting from the enhanced accuracy offered by the complete single-diode PV model.

Small-signal analysis is employed to linearize the system model and tune the PI controllers to ensure good response under any possible operating conditions. To validate the effectiveness of the proposed control scheme, simulations are first performed in MATLAB/Simulink considering noisy environment. Then, a $2 \mathrm{~kW}$ prototype converter is developed and tested under both static and dynamic irradiance conditions. The results validate the reliable and efficient operation of the control technique.

In Section II of the paper, the proposed control scheme is described in detail, while the MPP estimation algorithm is discussed in Section III. The linearization of the system model and tuning of the PI controller is presented in Section IV. Validation is provided through simulations in Section $\mathrm{V}$ and experimental tests in Section VI.

\section{POWER RESERVES CONTROL SCHEME}

The topology of a transformerless two-stage inverter and the block diagram of the proposed control are illustrated in Fig. 1. The dc/dc converter, hereafter referred to simply as the converter, regulates the operating point of the PV generator and adapts the output voltage to meet the dc link requirements. In the following, a boost converter is considered for simplicity, but

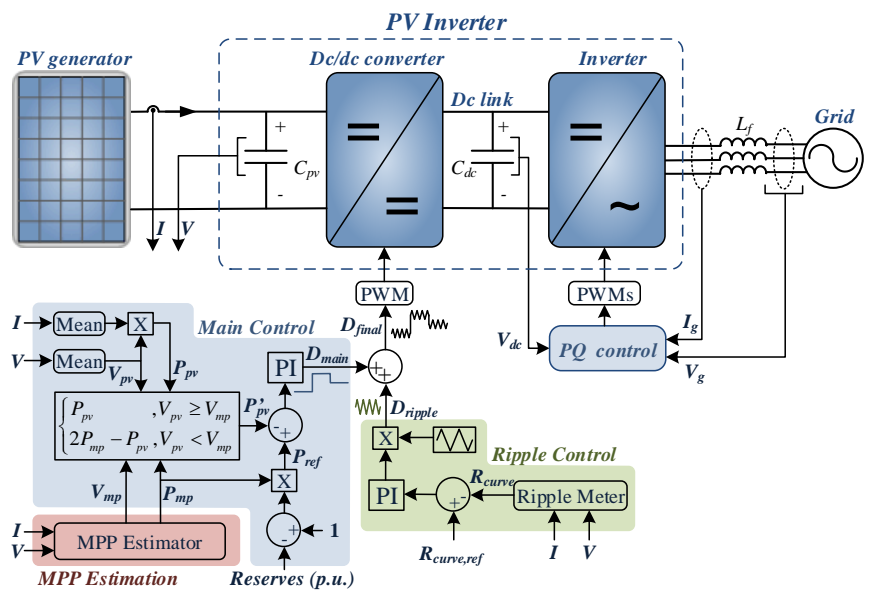

Fig. 1. Power circuit and control scheme of the proposed technique. the control scheme is applicable to any type of $\mathrm{dc} / \mathrm{dc}$ converter. The inverter performs the dc link voltage control and transfers the power to the gird, applying a P-Q control algorithm and implementing any ancillary services policy [4], [15].

In order for the PV system to maintain active power reserves, the converter has to regulate the PV generator to a suboptimal/reduced/curtailed power level, according to a reserves command. In Fig. 1, this is expressed as a reserves ratio, i.e. as a fraction of the available PV power (p.u.), while a direct power reserves command (in absolute $\mathrm{kW} / \mathrm{MW}$ ) is also possible. The overall controller consists of three individual subsystems, highlighted in color in Fig. 1. The Main Control block is responsible for regulating the duty cycle of the converter, $D_{\text {main }}$, to meet the reserve command requirement. The actual MPP of the PV array is continuously estimated through the MPP Estimation module, using available measurements of the PV generator's voltage and current. To guarantee the robustness of the MPP estimation, a Ripple Control module is employed to appropriately adjust the ripple on measurements, by adding a perturbation signal $D_{\text {ripple }}$ on $D_{\text {main }}$. All three subsystems operate at the same control period $T_{\text {control}}$, and are discussed in detail in the following sections.

\section{A. Main Control Module}

The objective of this module is to adjust the duty cycle $D_{\text {main }}$ to allow operation at a specific power reference $P_{\text {ref }}$, provided either externally by the grid operator or internally by a frequency response block. As $P_{\text {ref }}$ is a power reference, a power regulator is implemented, rather than a simple voltage controller tracking a voltage reference signal, which would not be effective to accurately follow power commands.

Since the relationship between power and duty cycle is not monotonic, a special manipulation of the measurements is necessary, as shown in Fig. 1. To facilitate understanding, an indicative $P-V$ curve of a PV string is shown in Fig. 2 (blue continuous line), along with the desired power reference level $P_{\text {ref }}$ (green dotted line). There are two possible operating points lying at either side of the MPP: Operating Point 1 (blue square marker) and Operating Point 2 (purple circle marker). Most of the relevant studies favor operation at the right-hand side of the $P-V$ curve [5], [6], [9], [11], [13], i.e. at voltages greater than the MPP voltage, $V_{m p}$, rather than on the left part of the characteristic [3], [4], [7], [10]. This is because of the improved converter efficiency at a higher voltage [3], [10] and the faster dynamic response due to the steeper slope [7], [11]. Further and more importantly, in this case power regulation over the entire range from near-zero to maximum power $P_{m p}$ can be easily

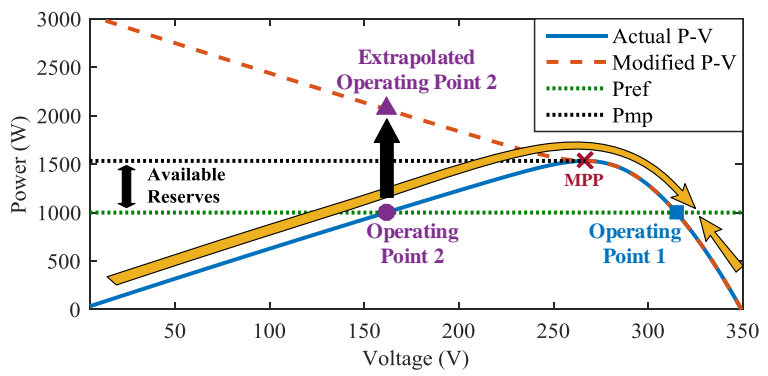

Fig. 2. Indicative $P-V$ characteristic and required power reserves level, illustrating operation at both sides of the $P$ - $V$ curve. 
achieved [11]. On the contrary, in the left-hand side of the characteristic minimum voltage restrictions of the $\mathrm{dc} / \mathrm{dc}$ converter will limit the maximum reserve levels supported [4].

However, even while operating at the right-hand side of the $P-V$ curve, the operating point may be shifted to the other side, e.g. when operating close to the MPP or under fast irradiance variations. The control scheme should be able to perform a transition towards Operating Point 1, from any location on the $P-V$ curve, as the yellow arrows indicate in Fig. 2. A simple PI controller would not be effective for this task over the entire range of possible operating points.

This is overcome by the Main Control scheme proposed in this paper (Fig. 1). The concept of the algorithm is graphically illustrated in Fig. 2. Instead of the actual $P-V$ curve (blue continuous line), the PI controller considers a modified version (red dashed line), found by mirroring the left-hand side of the $P-V$ curve against a horizontal line passing through the MPP. The modified curve is given by:

$$
P_{p v}^{\prime}= \begin{cases}P_{p v}, & V_{p v} \geq V_{m p} \\ 2 P_{m p}-P_{p v}, & V_{p v}<V_{m p}\end{cases}
$$

where the notations $V_{p v}, P_{p v}$ and $V_{m p}, P_{m p}$ refer to the voltage and power of the actual operating point and the MPP. $V_{p v}$ and $P_{p v}$ are calculated by averaging the measured voltage and power over a control period, while the MPP properties are provided by the MPP Estimation module (Fig. 1).

If the operating point is located on the left-hand section of the curve (e.g. Operating Point 2 in Fig. 2), then the modified power $P_{p v}^{\prime}$ from (1) (corresponding to the Extrapolated Operating Point 2 in Fig. 2) is fed to the PI controller, rather than the actual power measured. This results in a strongly negative error (Fig. 1) that shifts the operating point towards the right-hand side of the curve (e.g. to Operating Point 1 in Fig. 2). Thus, a monotonic relationship between power and duty cycle is established, retaining a smooth slope at the MPP region and a steeper negative slope at the left-hand side of the $P-V$ curve. The proposed control permits operation over the entire range of available power in a continuous manner, obviating any need to switch between operating modes (MPPT or Reserves) as done in other works [4], [10], [11], [13].

\section{B. MPP Estimation Module}

In order to estimate the MPP voltage and power while operating suboptimally, a least squares curve fitting method is introduced in this paper, graphically illustrated in Fig. 3. The fundamental equation of the single-diode PV model is fitted to a set of past measurements $\left(V_{i}, P_{i}\right)$ (green circle markers) around

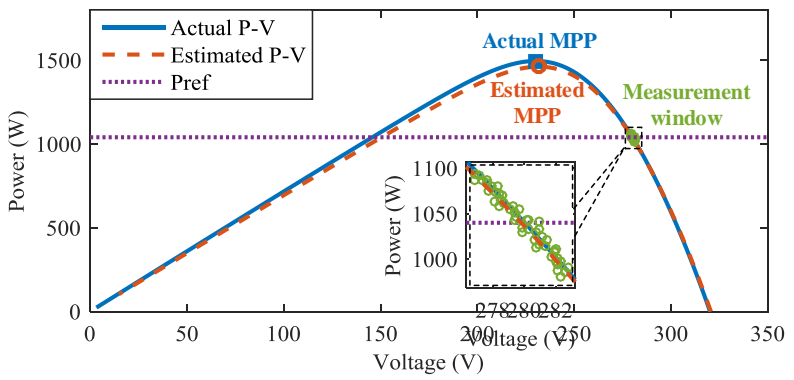

Fig. 3. Indicative scenario of applying curve fitting on noisy measurements to estimate the MPP, while maintaining power reserves. the current operating point, denoted as measurement window. The model parameters are thus estimated and the MPP (red circle marker) is determined. The window is created by variations of the operating point due to the inherent switching ripple of the converter, assisted by a perturbation signal deliberately introduced by the Ripple Control module. The samples maintained in the measurement window correspond to the last $T_{\text {control }}$ period. The mathematical formulation of the curve fitting method is described in Section III.

\section{Ripple Control Module}

MPPT algorithms are available in the literature utilizing the ripple in voltage and current measurements of the PV generator. The switching ripple caused by the power transistor is used in [16], whereas [17] relies on the oscillation of the instantaneous power transferred to the grid. Yet, the level of this inherent ripple may not suffice, as it depends on characteristics of the inverter, such as the switching frequency and the size of the filter capacitors [16], [17]. For this reason, standard MPPT algorithms, like $\mathrm{P} \& \mathrm{O}$ and INC, perturb the converter duty cycle to introduce additional variation of the operating point [18]. A triangular perturbation signal is superimposed on the duty cycle in [19] to provide a smoother oscillation of the operating point.

However, in all aforementioned methods the perturbation level remains constant regardless of the operating point on the $P-V$ curve. This leads to an unregulated level of ripple, as explained in the following. On the other hand, with the Ripple Control scheme shown in Fig. 1, the ripple intensity is continuously regulated to ensure an appropriate measurement window. This is achieved by adjusting the amplitude of a fixedfrequency triangular perturbation signal via a PI controller. Notably, this is the first study in literature to employ ripple correction in an active power reserves control scheme.

\section{1) Amplitude of $D_{\text {ripple }}$}

The oscillation of the operating point around the reference power can be quantified in terms of the corresponding voltage, current or power fluctuation. Yet, the robustness of the curve fitting algorithm essentially depends on the length of the measurement window on the $P$-V curve, rather than the power or voltage ripple, i.e. its projections on the $y$ - or $x$-axis. To quantify this length, the Euclidean distance of the boundary samples within the window can be used, assuming that the respective section of the $P-V$ curve included in the measurement window is approximately linear. The ripple metric thus introduced, denoted as curve ripple, $R_{\text {curve }}$, is given (in p.u.) by:

$$
R_{\text {curve }}=\sqrt{\left(\frac{V_{1}-V_{2}}{V_{o c 0}}\right)^{2}+\left(\frac{P_{1}-P_{2}}{P_{m p 0}}\right)^{2}}
$$

where $\left(V_{1}, P_{1}\right)$ and $\left(V_{2}, P_{2}\right)$ are the boundary samples within the measurement window; $V_{o c 0}$ and $P_{m p 0}$ are the nominal open circuit voltage and maximum power of the PV generator, used only for normalization purposes.

To facilitate understanding, in Fig. 4 two alternative approaches are examined: a triangular perturbation signal with a constant amplitude (green markers) as in [19], and adjustable perturbation amplitude to achieve a constant curve ripple $R_{\text {curve }}$ (red markers). Three operating conditions (A, B and C) are 


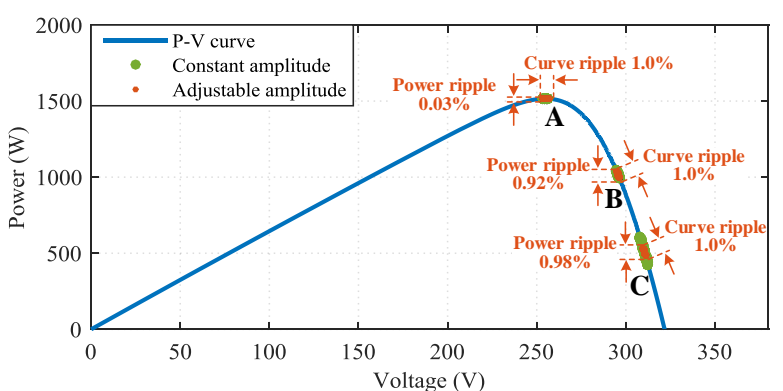

Fig. 4. Operating point oscillation applying a perturbation signal of constant or adjustable amplitude (proposed Ripple Control scheme).

examined, corresponding to widely different levels of reserves. With a constant perturbation amplitude, the resulting oscillation of the operating point varies significantly (green markers), being clearly excessive in case $\mathrm{C}$. On the contrary, the proposed Ripple Control scheme maintains the desirable curve ripple, regardless of the operating conditions (red markers).

Furthermore, with the proposed scheme (red markers), although the curve ripple is always equal to $1 \%$, the resulting power ripple varies depending on the slope of the $P-V$ curve at the operating region. At the MPP $(0 \%$ reserves, point A), the $P$ $V$ curve is nearly horizontal, leading to minimum power ripple and thus high MPPT efficiency. At other operating regions, where the slope of the $P-V$ curve is steeper, the power ripple is increased, yet never exceeding the respective curve ripple value (less than $1 \%$ in Fig. 4). Consequently, the Ripple Control scheme of Fig. 1 ensures an appropriate measurement window for successful curve fitting under any conditions, limiting at the same time the power fluctuations below the curve ripple level.

\section{2) Period of $D_{\text {ripple }}$}

The period of the perturbation signal is maintained constant and equal to the control period $T_{\text {control. }}$. Thus, the superposed ripple is filtered out by the Mean blocks of the Main Control module of Fig. 1 and does not affect the operation of the power controller. $T_{\text {control }}$ should be sufficiently small to permit adaptation under fast varying irradiance conditions, but not too small especially in presence of parasitic inductances and capacitances. In this paper, $T_{\text {control }}$ is set to $20 \mathrm{~ms}(50 \mathrm{~Hz})$, which provides satisfactory performance and lies beyond the frequency range of power-line flicker.

\section{REAL TIME MPP ESTIMATION ALGORITHM}

Several methods to estimate the MPP voltage and current in real-time, mainly for MPPT reasons, are available in the literature [3]-[7], [10], [11], [20]-[24]. Most of them utilize measurements of the PV generator voltage and current. In particular, a few past samples are used to fit a polynomial equation in [3], [4], [10], [11], [24] or a simplified single-diode model in [21], [22], whereas a curve fitting technique is applied to a larger set of previous measurements in [5], [6], [20], [23].

Although the curve fitting approach addresses the issue of noise satisfactorily, none of these methods employs the more accurate non-simplified single-diode PV model, due to its complexity. This is resolved in the following by reducing the unknowns from five to two, providing estimation accuracy and affordable computational cost at the same time. It is worth

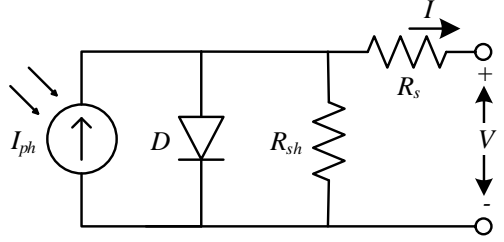

Fig. 5. Electrical equivalent circuit of the single-diode PV model.

noting that the proposed method is not limited only to MPP estimation; it calculates the five parameters of the single-diode model, essentially providing all $\mathrm{PV}$ generator properties, such as the $I-V$ and $P-V$ curves.

\section{A. Single-Diode PV Model}

The electrical equivalent circuit of the single-diode PV model adopted is depicted in Fig. 5. The five parameters of the model are the photocurrent $I_{p h}$, the diode saturation current $I_{s}$, the modified diode ideality factor $a$, the series resistance $R_{s}$ and the shunt resistance $R_{s h}$. This model applies to any PV system operating under uniform irradiance and temperature conditions, while its voltage-current equation is given by:

$$
\begin{gathered}
I=I_{p h}-I_{s}\left(e^{\frac{V+I R_{s}}{a}}-1\right)-\left(\frac{V+I R_{s}}{R_{s h}}\right) \Leftrightarrow \\
a \log \left[\frac{I_{p h}-I-\left(V+I R_{s}\right) / R_{s h}}{I_{s}}+1\right]-V-I R_{s}=0
\end{gathered}
$$

The five parameters depend on the PV modules properties, as well as on the irradiance $G$ and temperature $T$. Usually, these parameters are first determined at standard test conditions (STC) using datasheet information, and then are translated to the actual operating conditions. In this work, the translation equations given in [25] are adopted, as manipulated in [26]:

$$
\begin{gathered}
I_{p h}=I_{p h 0} G\left(1+a_{I s c} \Delta T\right) \\
I_{s}=I_{s 0} \lambda T^{3} e^{47.1\left(1-\frac{1}{\lambda T}\right)} \\
a=a_{0} \lambda T \\
R_{s}=R_{s 0} \\
R_{s h}=\frac{R_{s h 0}}{G}
\end{gathered}
$$

where the subscript " 0 " indicates parameter at STC and $a_{I s c}$ denotes the normalized temperature coefficient for the short circuit current. $\Delta T=T-T_{0}$ is the temperature deviation from STC temperature $T_{0}$, and $\lambda T=T / T_{0}$ the respective ratio (values in Kelvin). The coefficient 47.1 in the exponent of (6) incorporates the energy bandgap of silicon cells and other constants [26].

Given the five parameters at the actual operating conditions, the MPP voltage and current are easily determined by the explicit equations introduced in [27]:

$$
\begin{gathered}
V_{m p}=\left(1+\frac{R_{s}}{R_{s h}}\right) a(w-1)-R_{s} I_{p h}\left(1-\frac{1}{w}\right) \\
I_{m p}=I_{p h}\left(1-\frac{1}{w}\right)-\frac{a(w-1)}{R_{s h}}
\end{gathered}
$$

where $w=W\left\{I_{p h} e / I_{s}\right\}$ is an auxiliary parameter calculated using the Lambert $W$ function. Similar expressions are proposed in [28] and [29]. 


\section{B. Least Squares Curve Fitting}

As discussed in Section II.B, the LSQ curve fitting method fits the PV model's equation (3) or (4) to the measurement window samples, to determine the five parameters and then the MPP voltage and power. This is achieved by minimizing the difference between measurements (green circle markers in Fig. 3) and estimated values (red dashed line in Fig. 3). Due to the high slope of the right-hand side of the $I-V$ curve, it is more effective to express this deviation in terms of voltage, rather than current (especially when there is noise in measurements). Thus, (4) is used as the model's equation, rather than (3).

This is a non-convex optimization problem with a search space of five dimensions, which is very difficult to initialize and solve in this form [30]. To overcome this issue, the translation equations of the five parameters (5)-(9) are substituted into (4), leading to (12) below as the equation to be fitted, instead of (4) . Thus, the search space dimensions are limited to only two: the normalized irradiance $G$ and the temperature ratio $\lambda T$. The calculation of the reference values $I_{p h 0}, I_{s 0}, a, R_{s 0}$ and $R_{s h 0}$ is discussed in Section III.C. The resulting problem is convex, exhibiting a single minimum, it can be readily initialized using the STC values $\left(G_{0}=1, \lambda T_{0}=1\right)$, and is easily solved due to the different effects of irradiance and temperature on the $I-V$ curve. It is worth noting that this approach is in agreement with the theoretical investigation of [30], which concludes that only two of the five parameters are really independent.

The LSQ optimization method minimizes the sum of squared ordinal deviation between measurements and estimations, by zeroing the partial derivatives of (12) with respect to $G$ and $\lambda T$ [31]. Since this is a non-linear problem, the Levenberg-Marquadt algorithm is employed [32]:

$$
\beta^{k+1}=\beta^{k}-\left(J^{T} \times J+\lambda \cdot \operatorname{diag}\left(J^{T} \times J\right)\right)^{-1} \times J^{T} \times r^{k}
$$

where $\beta$ is the parameters vector $[G, \lambda T]^{\mathrm{T}}, J$ is the Jacobian matrix, $r$ is the residual, $\lambda$ a damping factor and $k$ the iteration.

The residual $r$ and its partial derivatives $\partial r / \partial G$ and $\partial r / \partial \lambda T$ required for the Jacobian matrix evaluation, are given by:

$$
\begin{aligned}
& r=a_{0} \lambda T \ln \left(\frac{I_{d}}{\lambda T^{3} I_{s 0}}\right)-47.1 a_{0}(\lambda T-1)-V-I R_{s 0} \\
& \frac{\partial r}{\partial G}=a_{0}\left(1+\frac{I}{I_{d}}\right) \frac{\lambda T}{G} \\
& \frac{\partial r}{\partial \lambda T}=a_{0}\left[\ln \left(\frac{I_{d}}{\lambda T^{3} I_{s 0}}\right)+G \lambda T \frac{I_{p h 0} I_{s 0} a_{I s c} T_{0}}{I_{d}}-50.1\right]
\end{aligned}
$$

where the auxiliary parameter $I_{d}$ (diode current) is given by:

$$
I_{d}=G I_{p h 0}\left[1+a_{I s c} T_{0}(\lambda T-1)\right]-I-G \frac{V+I R_{s 0}}{R_{s h 0}}
$$

Substituting (14)-(16) into (13) and after some manipulation, the iteration step is finally derived:

$$
\left[\begin{array}{c}
G \\
\lambda T
\end{array}\right]^{k+1}=\left[\begin{array}{c}
G \\
\lambda T
\end{array}\right]^{k}-\frac{1}{(1+\lambda)^{2} S_{020} S_{200}-S_{110}^{2}}\left[\begin{array}{c}
(1+\lambda) S_{020} S_{101}-S_{110} S_{011} \\
(1+\lambda) S_{020} S_{011}-S_{110} S_{101}
\end{array}\right]
$$

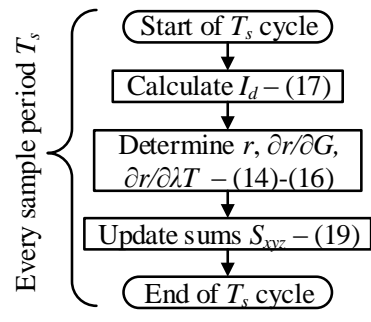

(a)

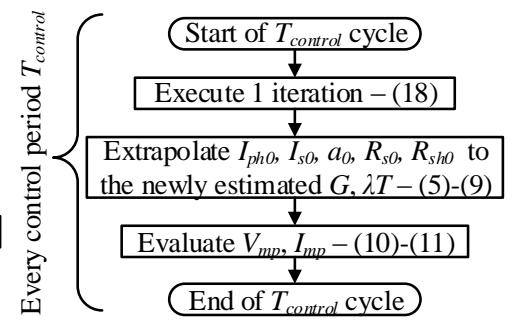

(b)
Fig. 6. Flowchart of the LSQ curve fitting, involving (a) update of all $S_{x y z}$ terms every sample period, and (b) MPP estimation every control period.

where $S_{x y z}$ stands for ( $n$ is the samples in the window):

$$
S_{x y z}=\sum_{i=1}^{n}\left(\frac{\partial r_{i}}{\partial G}\right)^{x}\left(\frac{\partial r_{i}}{\partial \lambda T}\right)^{y}\left(r_{i}\right)^{z}
$$

Hence, the proposed curve fitting algorithm consists of two nested procedures: first calculation (update) of summation terms (19) at every sampling period $T_{s}$ and then estimation of the MPP at the end of each control period $T_{\text {control }}$ employing the entire measurement window. As shown in the flowchart of Fig. 6(a), with every new measurement sample obtained, first $I_{d}$ is determined and then the residual and partial derivatives are calculated to update all sums $S_{x y z}$.

When one full window period $T_{\text {control }}$ has elapsed (Fig. 6(b)), one iteration of the Levenberg-Marquadt algorithm is performed to update $G$ and $\lambda T$, subsequently used to calculate the five parameters and determine the MPP voltage and current. A single iteration performed every $T_{\text {control }}$ suffices for continuous adaptation to the relatively slow changing environmental conditions; this way, the calculation burden is minimized, permitting implementation of the method on a typical microcontroller. For the Lambert $W$ function in (10)(11), the simplified series approximation of [26] is used.

\section{Calculation of the Reference Parameters}

The reference model parameters $I_{p h 0}, I_{s 0}, a_{0}, R_{s 0}$ and $R_{s h 0}$ of a PV system may be calculated either from datasheet information or a measured $I-V$ characteristic [26]. While the former approach is suitable for simulation studies, the latter provides greater accuracy when measurements from the actual PV system are available. This because the properties of a PV array often deviate from the datasheet for several reasons (manufacturing tolerances, ageing, cables resistance etc.).

In this work, the reference parameters are determined applying the simple explicit method of [33] on the measured $I$ $V$ characteristic of the system. The latter is obtained through a curve scan operation, varying the duty cycle of the converter from $0 \%$ to $100 \%$ within a short interval, e.g. 10 seconds. This procedure has to be performed initially when installing the system, and then be repeated periodically to account for longterm changes due to ageing or degradation. Since these changes are very slow, typically at a rate of $0.75 \%$ per year for crystalline PV modules [34], a scan frequency of once per month or year should suffice.

$$
a_{0} \lambda T \log \left(\frac{G I_{p h 0}\left[1+a_{I s c} T_{0}(\lambda T-1)\right]-I-G\left(V+I R_{s 0}\right) / R_{s h 0}}{I_{s 0} \lambda T^{3} e^{47.1(1-1 / \lambda T)}}\right)-V-I R_{s 0}=0
$$




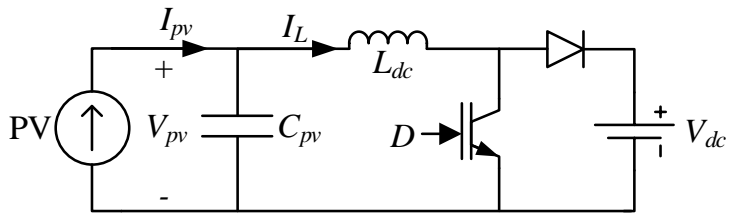

Fig. 8. Simplified electrical circuit model of the system, comprising the PV generator and the boost converter.

\section{Controller Design AND Stability ANalysis}

In this section, tuning of the PV generator output power PI regulator (Main Control block in Fig. 1) is discussed.

\section{A. System Model Linearization}

A simplified representation of the system comprising the PV generator and the boost converter is shown in Fig. 8. The former is modeled as a current source $I_{p v}$ that depends on the operating point; the output voltage $V_{d c}$ is considered to be kept at its reference value by the inverter control.

The continuous-time transfer function of the small-signal model of this circuit can be found in [35], with the duty cycle, $D(s)$, being the system input and the PV voltage, $V_{p v}(s)$, the system output. To introduce PV power, $P_{p v}(s)$, as the system output in place of $V_{p v}(s)$, the following relation is used between small perturbations $\Delta P_{p v}$ and $\Delta V_{p v}$ :

$$
\Delta P_{p v}=\left(I_{p v}+\frac{V_{p v}}{r_{p v}}\right) \Delta V_{p v}
$$

where $I_{p v}, V_{p v}$ and $r_{p v}=\Delta V_{p v} / \Delta I_{p v}$ are the current, voltage and dynamic resistance of the PV generator at the actual operating point. The linearized model derived is a typical second-order system, with a transfer function:

$$
G(s)=\frac{P_{p v}(s)}{\mathrm{D}(s)}=\frac{K_{0}}{s^{2}+2 \xi \omega_{0} s+\omega_{0}^{2}}
$$

where the gain $K_{0}$, the undamped natural frequency $\omega_{0}$ and the damping factor $\xi$ are given by:

$$
K_{0}=\frac{-V_{d c}}{L_{d c} C_{p v}}\left(I_{p v}+\frac{V_{p v}}{r_{p v}}\right) \quad \omega_{0}=\frac{1}{\sqrt{L_{d c} C_{p v}}} \quad \xi=\frac{-1}{2 r_{p v} C_{p v} \omega_{0}}
$$

Apparently, system dynamics are affected by the PV operating point through the parameters $I_{p v}, V_{p v}$ and $r_{p v}$.

\section{B. Closed Loop System}

The block diagram of the closed-loop system, including the power PI regulator of the Main Control module, is shown in Fig. 7. As discussed in Section II.A, using the modified PV power guarantees operation in the right-hand side of the $P-V$ curve, thus $P_{p v}$ is used as the feedback signal. The power error fed to the PI controller is normalized on the nominal PV power $P_{m p 0}$. The "delay" block in Fig. 7 is a first-order Pade approximation [35] of the aggregate (digital) delay $T_{d}$ corresponding to the PWM and execution time delays (in this case equal to the switching period $T_{c}=50 \mu \mathrm{s}$ ). Therefore, the

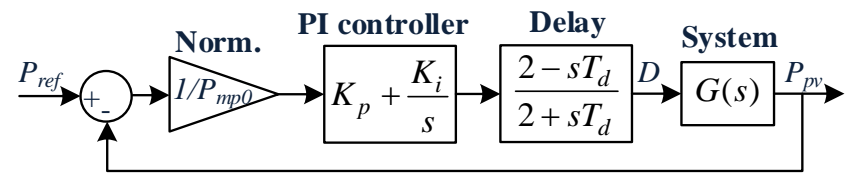

Fig. 7. Closed-loop block diagram of the linearized system. closed-loop transfer function is:

$$
H(s)=\frac{K_{0}}{P_{m p 0}} \frac{\left(K_{p} s+K_{i}\right)\left(2-s T_{d}\right)}{s\left(s^{2}+2 \xi \omega_{0} s+\omega_{0}^{2}\right)\left(2+s T_{d}\right)}
$$

For the hardware implementation of the PI controller, a bilinear transformation of the continuous-time transfer function to the Z-domain is employed [36]:

$$
y[n]=K_{p}(x[n]-x[n-1])+\frac{T_{\text {control }}}{2} K_{i}(x[n]+x[n-1])+\mathrm{y}[\mathrm{n}-1]
$$

where $y[n]$ and $x[n]$ are the output and input signals at step $n$.

\section{Selection of PI Controller Gains}

The root locus diagram of (23) is depicted in Fig. 10 for the indicative case of STC and $0 \%$ reserves, using $K_{p}$ as a varying parameter while considering a time constant $\tau=K_{p} / K_{i}=2 \mathrm{~ms}$ for the controller ( $1 / 10$ of the control period $\left.T_{\text {control }}\right)$. Selected gains and other system parameters are given in Table I.

Bode plots of the open-loop transfer function are shown in Fig. 9 for operation at various reserve levels; minimum stability margins are indicated with circle markers. Plots do not differ considerably, with the exception of the magnitude diagram at $0 \%$ reserves. The phase margin is close to 90 degrees for low reserve ratios, while it is reduced down to 42 degrees in the worst case of $100 \%$ reserves (blue marker).

The system remains stable at any possible operating conditions. This is confirmed by the diagram in Fig. 11, illustrating the phase margin variation with the operating reserves for six cases of widely different irradiance and temperature conditions. In the worst cases, a phase margin near

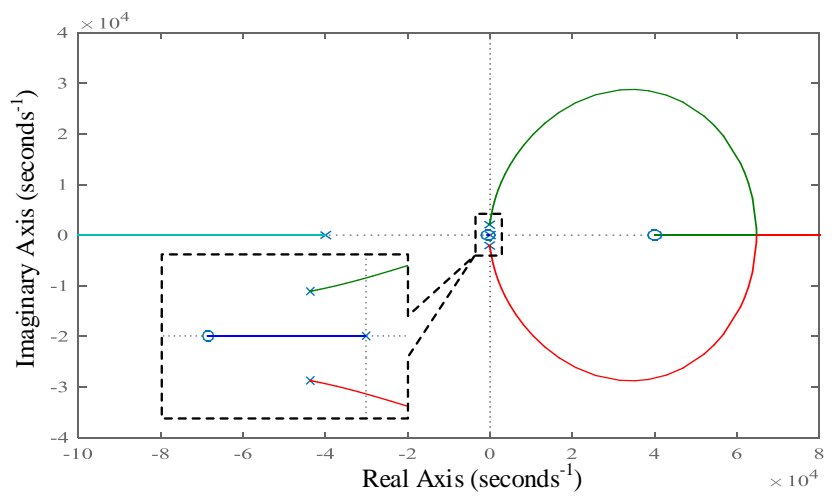

Fig. 10. Root locus diagram of the closed-loop transfer function (STC and $0 \%$ reserves), varying $K_{p}$ while considering a time constant $\tau=K_{p} / K_{i}=2 \mathrm{~ms}$.

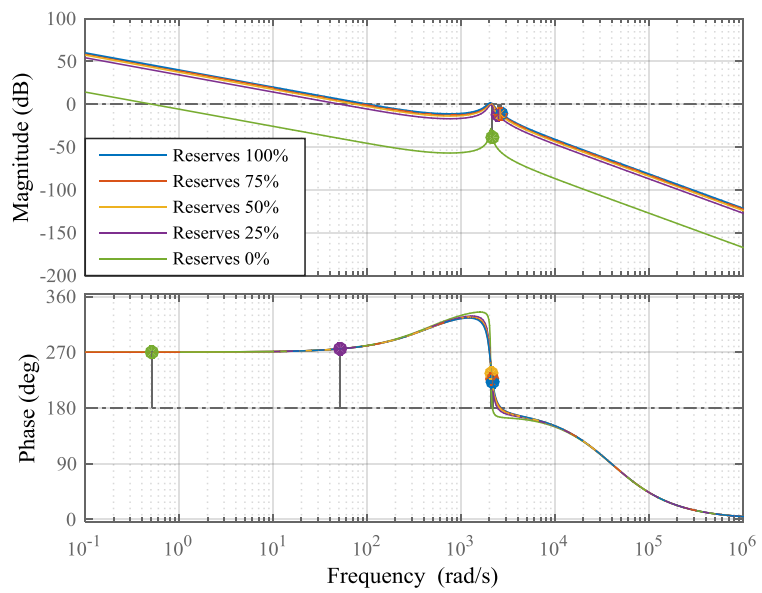

Fig. 9. Bode plots of the open-loop transfer function at various reserve levels (STC). Minimum stability margins indicated with circle markers. 


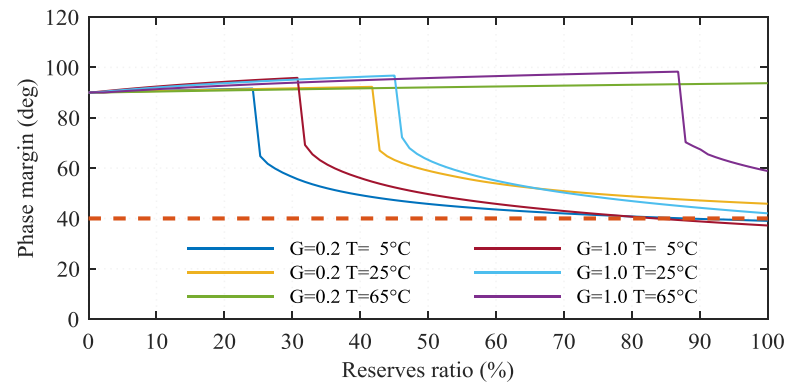

Fig. 11. Phase margin variation with the reserves ratio for six scenarios of widely different irradiance and temperature conditions.

40 degrees is obtained, which is fully acceptable [37], [38].

A similar process can be employed to tune the ripple PI controller. Here, the same gains are used as for the main PI regulator (Table I).

\section{SimULATIONS IN MATLAB/SimULINK}

To investigate the effectiveness of the proposed control scheme, simulations are first performed in MATLAB/ Simulink for a $2 \mathrm{~kW} \mathrm{PV}$ string coupled to a boost converter which in turn feeds in a grid connected inverter, as shown in Fig. 1. The parameters of the investigated system are given in Table I, corresponding also to the experimental setup of Section VI.

System operation is simulated over a $30 \mathrm{~s}$ period, during which the reserve command varies from $0 \%$ to $90 \%$ (Fig. 12(a)). To investigate the performance of the algorithm at the most demanding conditions, simultaneous irradiance and temperature variations are considered (Fig. 12(b)), assuming a trapezoidal profile and high rates of change $\left(50 \mathrm{~W} /\left(\mathrm{m}^{2} \mathrm{~s}\right)\right.$ and 1 ${ }^{\circ} \mathrm{C} / \mathrm{s}$ respectively), while Additive White Gaussian Noise (AWGN) is superposed on the measurements ( $\mathrm{SNR}=75)$. Two

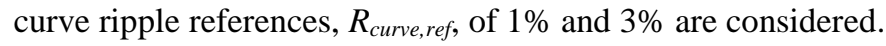

In Fig. 12(a), it is shown that the controller successfully tracks step changes of the power reserves command (red dashed line), with a response time of around $0.4 \mathrm{~s}$. Satisfactory results are obtained for both ripple levels, although the PV generator power expectedly exhibits increased flactuqation in the $3 \%$

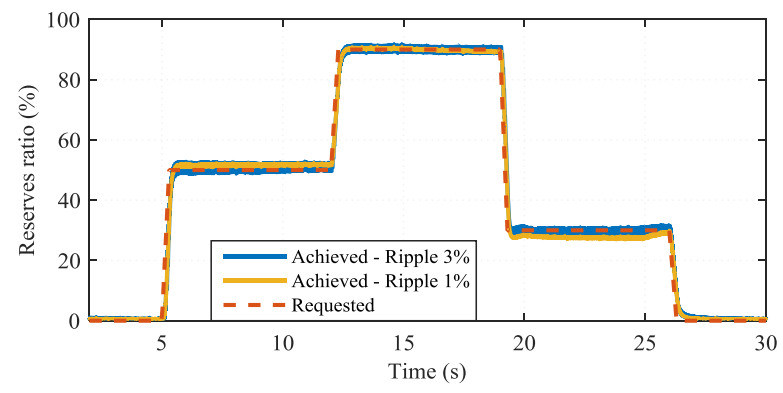

(a)

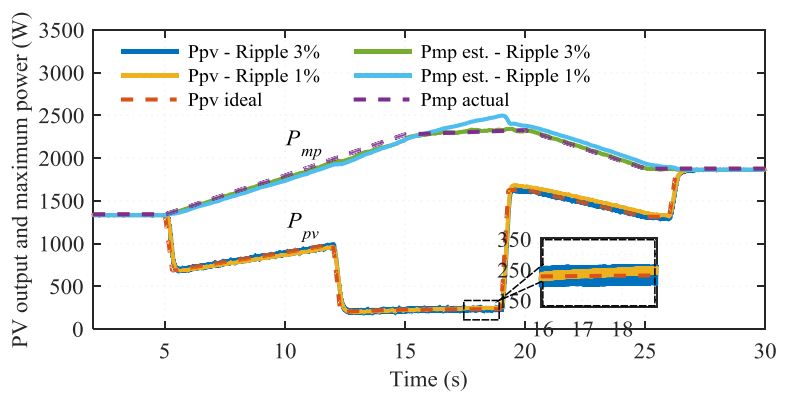

(c)
TABLE I

CHARACTERISTICS OF THE SIMULATED PV SYSTEM

\begin{tabular}{lr||lr|}
\hline Parameter & Value & Parameter & Value \\
\hline Nominal power $\boldsymbol{P}_{\boldsymbol{m} p \boldsymbol{0}}$ & $2 \mathrm{~kW}$ & Dc link voltage $\boldsymbol{V}_{\boldsymbol{d c}}$ & $700 \mathrm{~V}$ \\
\hline Input capacitance $\boldsymbol{C}_{\boldsymbol{p} v}$ & $470 \mu \mathrm{F}$ & Output capacitance $\boldsymbol{C}_{\boldsymbol{d c}}$ & $1175 \mu \mathrm{F}$ \\
Converter inductance $\boldsymbol{L}_{\boldsymbol{d}}$ & $500 \mu \mathrm{H}$ & Switching frequency $\boldsymbol{F}_{\boldsymbol{c}}$ & $20 \mathrm{kHz}$ \\
\hline Sampling frequency $\boldsymbol{F}_{\boldsymbol{s}}$ & $20 \mathrm{kHz}$ & Control frequency $\boldsymbol{F}_{\text {control }}$ & $50 \mathrm{~Hz}$ \\
\hline $\boldsymbol{K}_{p}$ of main PI controller & 0.01 & $\boldsymbol{K}_{\boldsymbol{i}}$ of main PI controller & 5.0 \\
\hline $\boldsymbol{K}_{\boldsymbol{p}}$ of ripple PI controller & 0.01 & $\boldsymbol{K}_{\boldsymbol{i}}$ of ripple PI controller & 5.0 \\
\hline
\end{tabular}

$R_{\text {curve, ref }}$ scenario (blue line). In Fig. 12(b), the irradiance and temperature variations are illustrated, along with the respective estimated values. While a 3\% ripple level ensures accurate estimation over the entire simulation period (blue and green lines), with $1 \%$ ripple the estimation error becomes noticeable (yellow and light blue lines), especially at 15-19 s, where both the reserves and the irradiance become maximum.

The estimated maximum power $P_{m p}$ and the output power $P_{p v}$ of the PV generator (PV side) are shown in Fig. 12(c). While the estimation error is imperceptible in the $3 \%$ case (green line), it reaches $7 \%$ for $1 \%$ ripple (light blue line). The PV generator output power meets the regulation requirements (red dashed line) in both cases. In Fig. 12(d), the operating windows on the respective $P-V$ curves are illustrated at four indicative instances. The measurement window for the 3\% ripple is larger (yellow markers), compared to the $1 \%$ case (red markers), resulting in a near-perfect match of the estimated $P-V$ curve (yellow dashed line) to the actual characteristic (blue line). This figure is indicative of the capabilities for accurate real-time estimation of all five model parameters under varying conditions.

The results at the grid side of the system are show in Fig. 12(e)-(g). The actual power $P_{\text {grid }}$ fed into the grid is depicted in Fig. 12(e) for the two ripple cases, exhibiting good tracking of the reference (red dashed line) and negligible ripple, as further discussed below. The dc link voltage $V_{d c}$, shown in Fig. 12(f), presents spikes of less than $7 \mathrm{~V}$ during reserves changes. As expected, the 3\% ripple case results in increased voltage fluctuation, yet not exceeding $2 \mathrm{~V}$ peak-to-peak. Fluctuation is larger while maintaining $0 \%$ reserves $(0-5 \mathrm{~s}$ and $26-30 \mathrm{~s}$ time

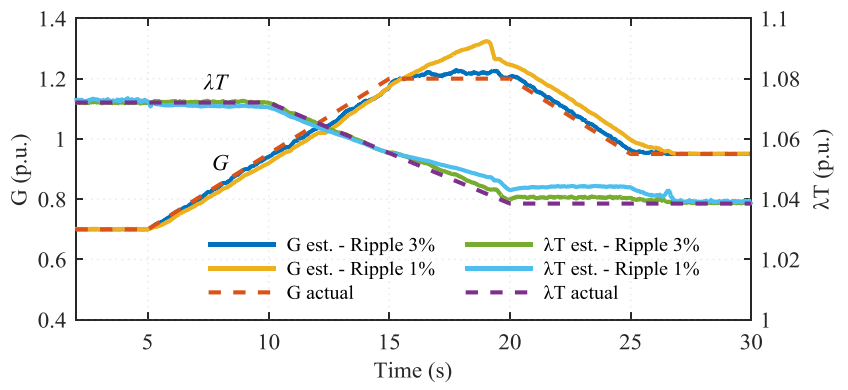

(b)

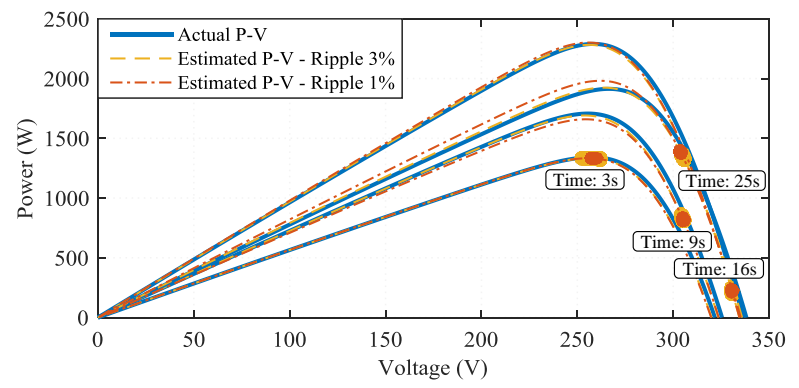

(d) 


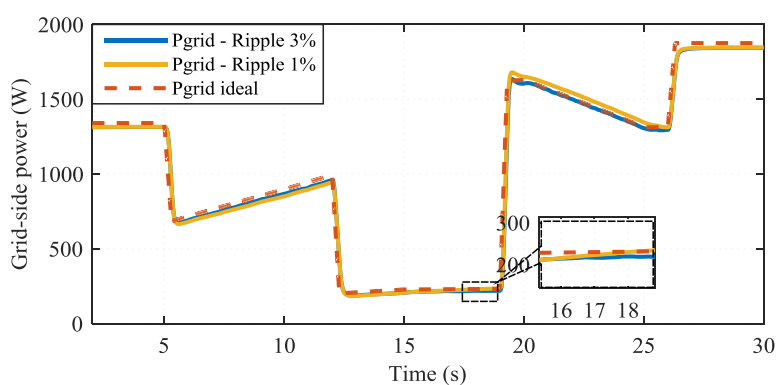

(e)

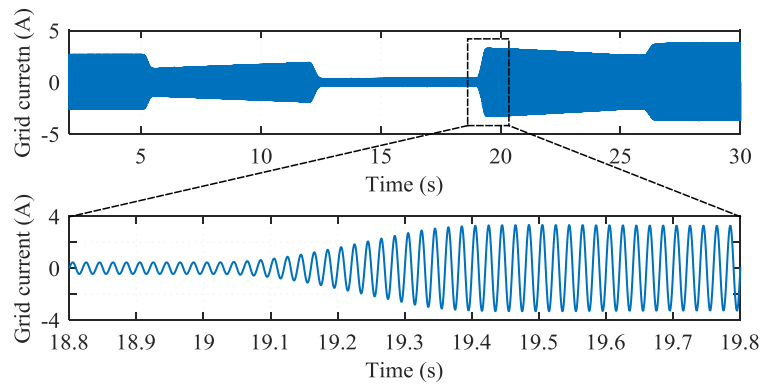

(g)

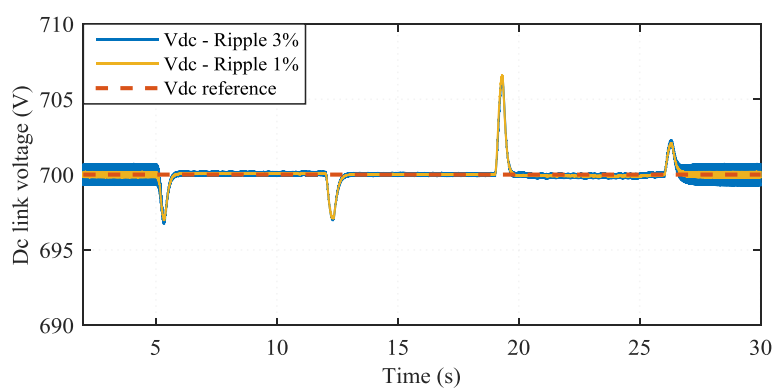

(f)

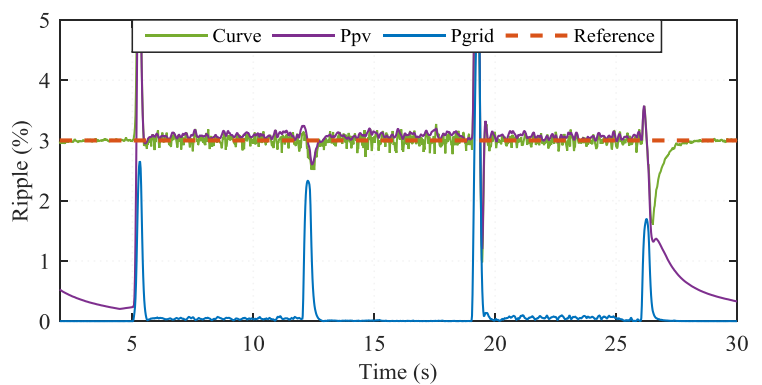

(h)

Fig. 12. Simulation of the proposed control scheme in MATLAB/Simulink for a $2 \mathrm{~kW}$ PV system, in presence of measurement noise (SNR 75), considering two reference ripple levels: $1 \%$ and 3\%. (a) Reserves ratio (requested and achieved), (b) irradiance and temperature (actual and estimated), (c) PV output power (ideal and achieved) and maximum available power (actual and estimated), (d) measurement window and $P$ - $V$ curve (actual and estimated) at four indicative instances, (e) power fed into the grid (ideal and achieved), (f) dc link voltage (reference and achieved), (g) grid current, and (h) curve ripple (reference and actual) and resulting $P_{p v}$ and $P_{\text {grid }}$ power ripples, for the $3 \% R_{\text {curve, }}$ se scenario.

intervals), as in this case the voltage ripple becomes maximum (flat section of the $P$ - $V$ curve); yet, this voltage fluctuation is not reflected to the output. The line current to the grid is illustrated in Fig. 12(g), presenting a response time of $0.4 \mathrm{~s}$ in the worst case (zoom box).

Fig. 12(h) illustrates the effectiveness of the Ripple Control module for the $3 \% R_{\text {curve, ref }}$ case. The curve ripple (green line) effectively tracks its 3\% reference (red dashed line), except at step changes of the reserve command, when a short time of around $1 \mathrm{~s}$ is needed to adapt to the new operating point. The ripple of the PV generator power $P_{p v}$ (purple line) is very low when operating at the MPP (0\% reserves) (0-5 s and 26-30 s time intervals), leading to high MPPT efficiency greater than $99 \%$ in this mode. When operating with substantial reserves, $P_{p v}$ fluctuation is at the same level as the curve ripple (measured slightly higher due to noise). In any case, the output power of the system at the grid side (blue line) remains very smooth (ripple lower than $0.1 \%$ in steady-state), due to the filtering effect of the dc link capacitors and the inverter control.

The main conclusion from this investigation is that a curve ripple level of 2-3\% is adequate for accurate MPP estimation in the presence of noise and rapidly changing environmental conditions. At MPP operation ( $0 \%$ reserves), MPPT efficiency

TABLE II

COMPONENTS OF THE EXPERIMENTAL SETUP

\begin{tabular}{|c|c|c|c|}
\hline Component & Model & Values/Type & Manufacturer \\
\hline $\begin{array}{l}\text { PV String (12 } \\
\text { modules) }\end{array}$ & YL165 & $165 \mathrm{~W}_{\mathrm{p}}, \mathrm{mc}-\mathrm{Si}$ & Yingli Solar \\
\hline Switching device & C2M0080120D & $\begin{array}{c}\text { 1200V/36A SiC } \\
\text { MOSFET }\end{array}$ & Cree \\
\hline Microcontroller & TMS320F28335 & $150 \mathrm{MHz}$ clock & Texas Instr. \\
\hline $\mathbf{J}$ & $\begin{array}{l}\text { TMS320F28335 } \\
\text { docking station }\end{array}$ & $\begin{array}{l}\text { On-board USB } \\
\text { JTAG emulation }\end{array}$ & Texas In \\
\hline Oscilloscope & TBS1000 & $60 \mathrm{MHz}, 4-\mathrm{Ch}$ & Tektronix \\
\hline
\end{tabular}

is very high and the resulting power ripple at the PV side is negligible, while in power reserves mode it is effectively filtered out to a level well below $1 \%$ at the grid side.

\section{EXPERIMENTAL VALIDATION}

The experimental setup built to validate the proposed controller is depicted in Fig. 13 and corresponds to the system presented in Fig. 1. A $2 \mathrm{~kW}$ PV string is connected to a boost converter prototype that feeds a resistive load for simplicity. The main characteristics of the converter are summarized in Table I. Information on the basic components is given in Table II. A SiC MOSFET is used as a switching device for increased efficiency, while the entire control scheme is implemented in a $150 \mathrm{MHz}$ microcontroller. The user interacts via an interface card, employing a LCD display and buttons, while the recorded data are transferred to a computer using a JTAG Emulator. All experimental tests are conducted with $3 \%$ curve ripple.

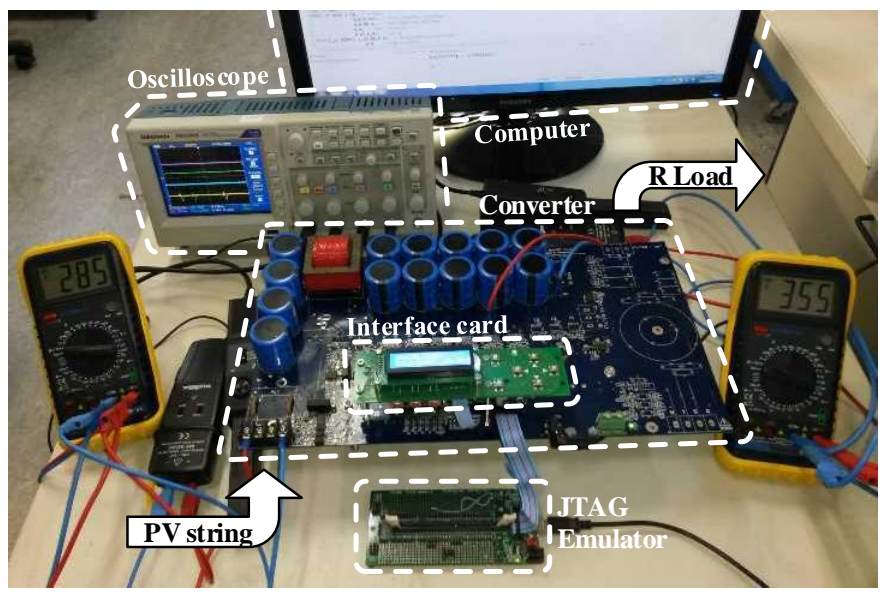

Fig. 13. Experimental setup used to validate the proposed control scheme. 


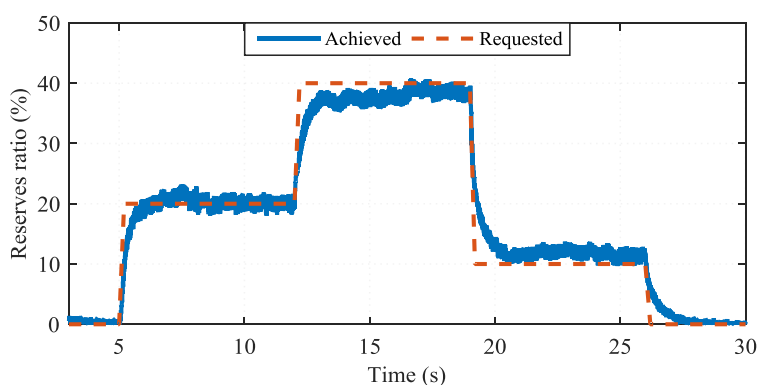

(a)

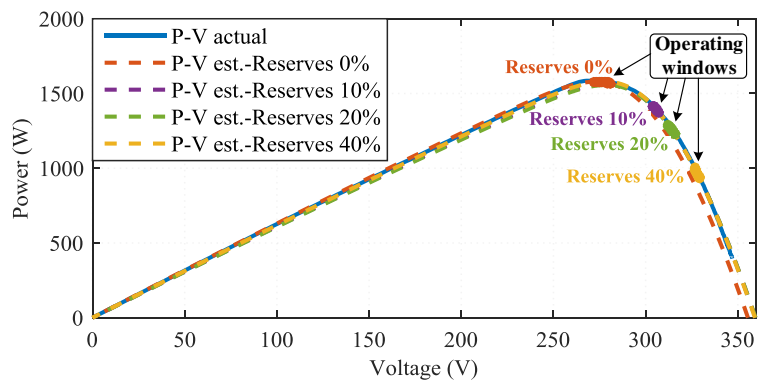

(c)

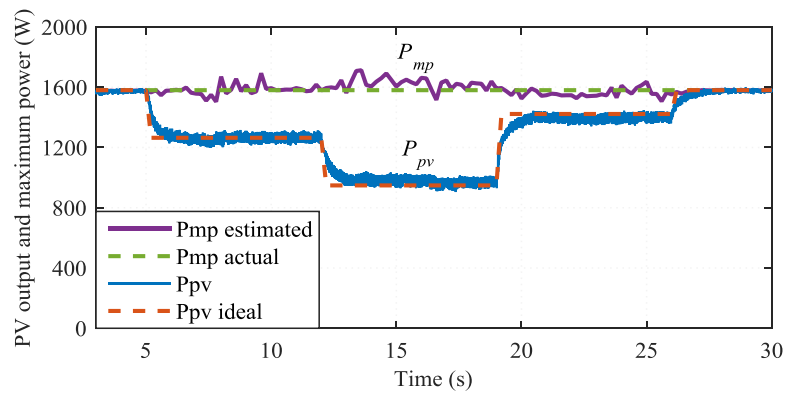

(b)

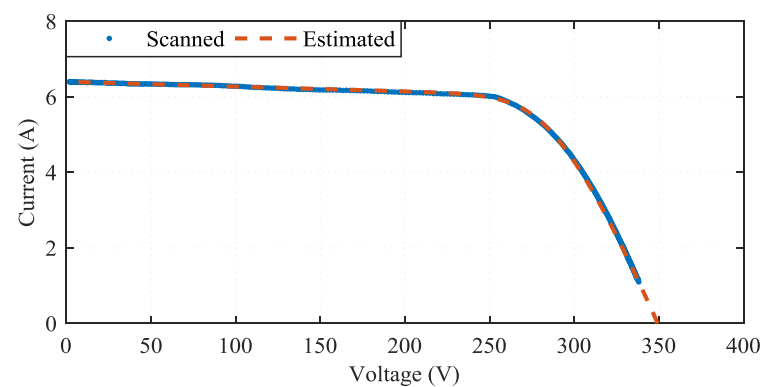

(d)

Fig. 14. Experimental results of the proposed control scheme for a $2 \mathrm{~kW}$ PV string at constant irradiance conditions, obtained via JTAG emulation. (a) Reserves ratio (requested and achieved), (b) PV output power (ideal and achieved) and maximum available power (actual and estimated), (c) operating windows on estimated $P$ - $V$ curves for various reserve levels, and (d) $I$ - $V$ curve (scanned and estimated) at reference conditions.

\section{A. PV String Testing under Constant Irradiance Conditions}

In this section, the entire PV string operates under constant irradiance to evaluate the performance of the controller in steady state conditions. The proposed converter control is applied, imposing changes to the instructed reserve levels, as shown in Fig. 14(a), over a $30 \mathrm{~s}$ interval of constant irradiance. From the diagrams in Fig. 14 it is evident that the reserve command is successfully implemented throughout the experiment (Fig. 14(a)), while the maximum power estimation is sufficiently accurate and the PV output power tracks its reference, as shown in Fig. 14(b). The actual $P_{m p}$ (green dashed line in Fig. 14(b)) is determined by the mean output power recorded during MPPT mode intervals (0-5 $\mathrm{s}$ and 26-30 s), when the string operates at $0 \%$ reserves.

Four measurement windows recorded during the testing interval that correspond to different levels of reserves $(0-40 \%)$ are shown in Fig. 14(c). The respective estimated (dashed lines) and actual (continuous line) $P-V$ curves are shown in different colors, the latter found via a curve scan performed afterwards. It is worth noting that window lengths are slightly different in the four cases, due to measurement noise that causes a small deviation of the achieved curve ripple from the $3 \%$ reference.

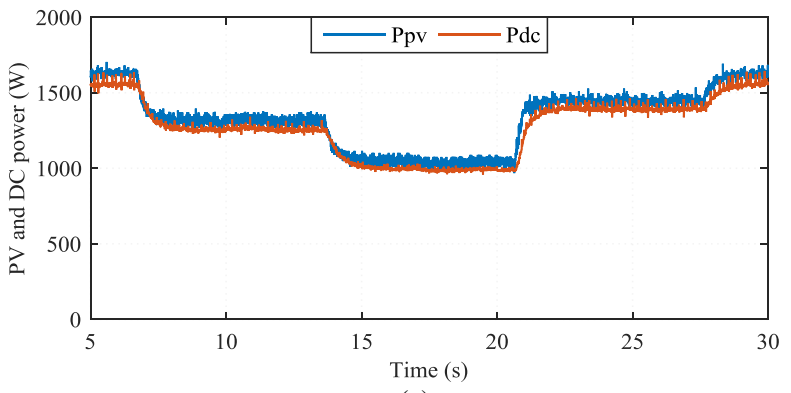

(a)
Nevertheless, all four estimated curves practically coincide with the actual (measured) one, validating estimation accuracy over the entire range of the $P-V$ curve.

The extraction process of the reference parameters, which was performed prior to the experiment (different day and time), is validated in Fig. 14(d). The measured (scanned) $I-V$ characteristic and the one reconstructed using the extracted parameters practically coincide with each other.

The induced power ripple is further evaluated in the oscillograms of Fig. 15. The converter output power $P_{d c}$ (red line) presents a much lower ripple than the PV power $P_{p v}$ (blue line), while the slight difference between their mean values observed in Fig. 15(a) is due to the converter losses. In Fig. 15 (b), four intervals of operation at different reserve levels are illustrated on the same diagram. The $P_{p v}$ fluctuation (blue line) strongly depends on the reserve command, being negligible at MPP operation (reserves 0\%). The MPPT efficiency in this case is measured close to $99 \%$. The ripple of the output power $P_{d c}$ (red line) is essentially due to converter switching and measurement noise: an FFT analysis of $P_{d c}$ reveals a $50 \mathrm{~Hz}$ ripple component of only $0.1 \%$ of the dc component.

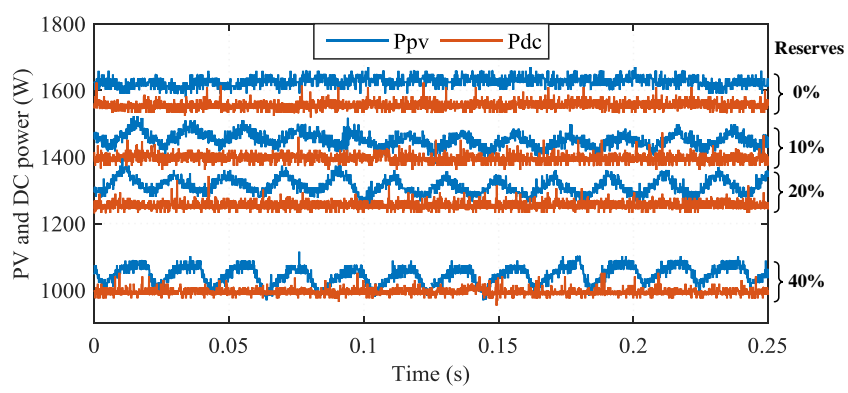

(b)

Fig. 15. Oscillograms of the measured power at the input and output of the converter ( $2 \mathrm{~kW}$ PV string at constant irradiance) for (a) the entire test duration and (b) $250 \mathrm{~ms}$ periods at different reserve levels. 


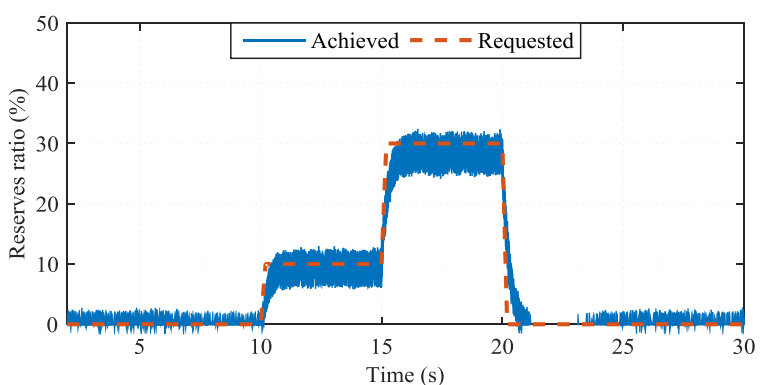

(a)

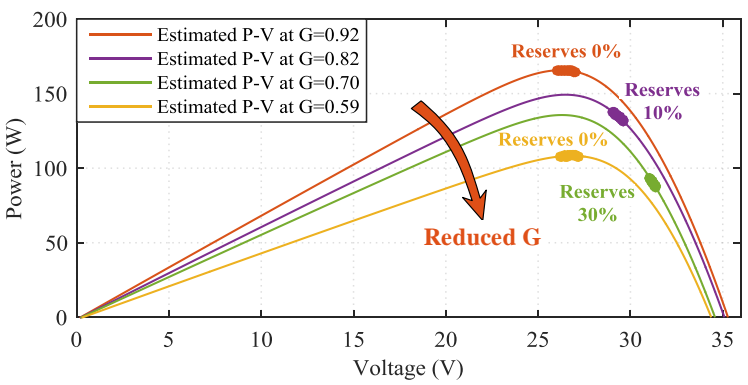

(c)

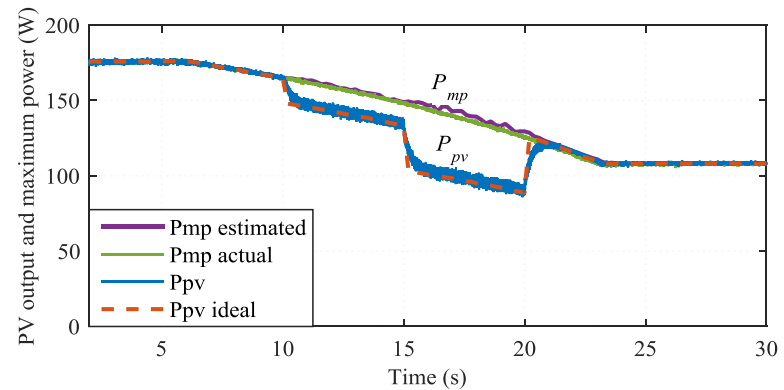

(b)

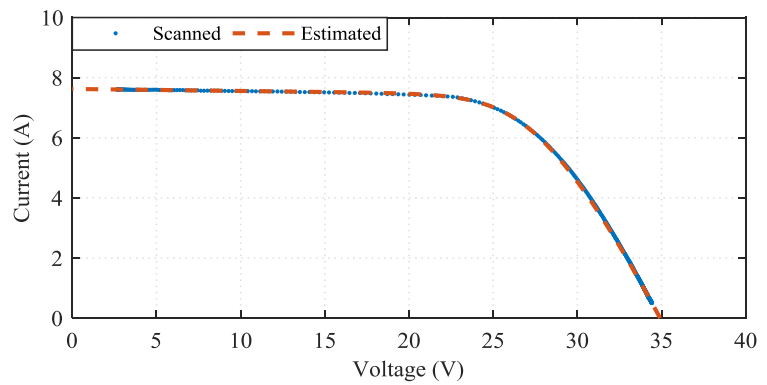

(d)

Fig. 16. Experimental results of the proposed control scheme for a single PV module (Perlight PLM-250P-60) at varying irradiance conditions, obtained via JTAG emulation. (a) Reserves ratio (requested and achieved), (b) PV output power (ideal and achieved) and maximum available power (actual and estimated), (c) operating windows and estimated $P-V$ curves at four different times, and (d) $I-V$ curve (scanned and estimated) at reference conditions.

\section{B. PV Module Testing under Variable Irradiance Conditions}

In order to validate the effectiveness of the proposed converter control under rapidly changing environmental conditions, a single PV module is used as a source, rather than the entire string. This way, fast irradiance variations are emulated by changing the module's tilt angle within a few seconds (irradiance reduced by $410 \mathrm{~W} / \mathrm{m}^{2}$ in $17 \mathrm{~s}$, at a rate of almost $25 \mathrm{~W} / \mathrm{m}^{2}$ per second). This procedure is performed twice: first the system operates with the reserve command profile of Fig. 16(a); then the experiment is repeated, with the converter running in MPPT mode ( $0 \%$ reserves) to acquire the actual maximum power, for comparison reasons.

The results are depicted in Fig. 16. The achieved power reserve levels (blue line) match the requested ones (red dashed line) in Fig. 16(a), while the estimated $P_{m p}$ (purple line) in Fig. 16(b) almost coincides with the actual (green line). Hence the good match between the produced power (blue line) and its reference (red dashed line) throughout the experiment.

In Fig. 16(c), four measurement windows recorded are depicted along with the respective estimated $P$ - $V$ curves. Again, the achieved curve ripple is not exactly $3 \%$, hence the small difference observed in the window lengths. However, this does not impact estimation accuracy, as discussed above. Successful extraction of the PV module reference parameters is verified in Fig. 16(d), performed a different day than the experiment. This test demonstrates the excellent performance of the controller under fast irradiance variations, as well.

\section{CONCLUSION}

In this paper, a new control scheme is introduced for the $\mathrm{dc} / \mathrm{dc}$ converter of a two-stage PV system, in order to maintain active power reserves over the entire operating range of the system (from near-zero to $100 \%$ of the maximum available power). The core element and novel feature of the proposed scheme is the real-time estimation of the MPP and model parameters via a curve fitting method that employs the fundamental single-diode PV model. No extra energy storage system or irradiance and temperature sensors are required, keeping the system cost and complexity to a minimum.

The stability of the proposed control strategy is analytically assessed and its effectiveness is validated through simulations and experimental testing at constant and varying irradiance conditions, using a $2 \mathrm{~kW}$ converter prototype. The results confirm estimation accuracy and reliable operation under the most demanding conditions.

\section{REFERENCES}

[1] Technical Guideline, "ENTSO-E network code for requirements for grid connection applicable to all generators," ENTSO-E, Mar. 2013.

[2] "Technical requirements for the connection to and parallel operation with low-voltage distribution networks," VDE-AR-N 4105, 2011.

[3] S. Nanou, A. Papakonstantinou, and S. Papathanassiou, "Control of a $\mathrm{PV}$ generator to maintain active power reserves during operation," in Proc. 27th Eur. Photovolt. Sol. Energy Conf. Exhib. (EU PVSEC 2012), Frankfurt, Germany, Sep. 2012, pp. 4059-4063.

[4] S. I. Nanou, A. G. Papakonstantinou, and S. A. Papathanassiou, "A generic model of two-stage grid-connected PV systems with primary frequency response and inertia emulation," Electr. Power Syst. Res., vol. 127, pp. 186-196, Oct. 2015.

[5] E. Batzelis, S. Nanou, and S. Papathanassiou, "Active power control in PV systems based on a quadratic curve fitting algorithm for the MPP estimation," in Proc. 29th Eur. Photovolt. Sol. Energy Conf. Exhib. (EU PVSEC 2014), Amsterdam, The Netherlands, Sep. 2014, pp. 3036-3040.

[6] E. Batzelis, T. Sofianopoulos, and S. Papathanassiou, "Active power control in PV systems using a curve fitting algorithm based on the single-diode model," in Proc. 31 st Eur. Photovolt. Sol. Energy Conf. Exhib. (EU PVSEC 2015), Hamburg, Germany, Sep. 2015, pp. $2402-$ 2407.

[7] H. Xin, Z. Lu, Y. Liu, and D. Gan, "A center-free control strategy for the coordination of multiple photovoltaic generators," IEEE Trans. Smart Grid, vol. 5, no. 3, pp. 1262-1269, May 2014.

[8] W. A. Omran, M. Kazerani, and M. M. A. Salama, "Investigation of methods for reduction of power fluctuations generated from large 
grid-connected photovoltaic systems," IEEE Trans. Energy Convers., vol. 26, no. 1, pp. 318-327, Mar. 2011.

[9] V. A. K. Pappu, B. Chowdhury, and R. Bhatt, "Implementing frequency regulation capability in a solar photovoltaic power plant," in Proc. North Am. Power Symp. 2010 (NAPS 2010), Arlington, TX, US, Sep. 2010.

[10] Y. Liu, L. Chen, L. Chen, H. Xin, and D. Gan, "A Newton quadratic interpolation based control strategy for photovoltaic system," in Proc. Int. Conf. Sustain. Power Gener. Supply (SUPERGEN 2012), Hangzhou, China, Sep. 2012, vol. 2012, no. 611 CP.

[11] H. Xin, Y. Liu, Z. Wang, D. Gan, and T. Yang, "A new frequency regulation strategy for photovoltaic systems without energy storage," IEEE Trans. Sustain. Energy, vol. 4, no. 4, pp. 985-993, Oct. 2013.

[12] B.-I. Craciun, T. Kerekes, D. Sera, and R. Teodorescu, "Frequency support functions in large PV power plants with active power reserves," IEEE J. Emerg. Sel. Top. Power Electron., vol. 2, no. 4, pp. 849-858, Dec. 2014

[13] D. Wu, F. Tang, T. Dragicevic, J. C. Vasquez, and J. M. Guerrero, "Autonomous active power control for islanded AC microgrids with photovoltaic generation and energy storage system," IEEE Trans. Energy Convers., vol. 29, no. 4, pp. 882-892, Dec. 2014.

[14] Y. Liu, H. Xin, Z. Wang, and T. Yang, "Power control strategy for photovoltaic system based on the Newton quadratic interpolation," IET Renew. Power Gener., vol. 8, no. 6, pp. 611-620, Aug. 2014.

[15] S. Manias, Power Electronics and Motor Drive Systems. Elsevier Science, 2016

[16] T. Esram, J. W. Kimball, P. T. Krein, P. L. Chapman, and P. Midya, "Dynamic Maximum Power Point Tracking of Photovoltaic Arrays Using Ripple Correlation Control," IEEE Trans. Power Electron., vol. 21, no. 5, pp. 1282-1291, Sep. 2006.

[17] D. Casadei, G. Grandi, and C. Rossi, "Single-phase single-stage photovoltaic generation system based on a ripple correlation control maximum power point tracking," IEEE Trans. Energy Convers., vol. 21, no. 2, pp. 562-568, Jun. 2006.

[18] T. Esram and P. L. Chapman, "Comparison of photovoltaic array maximum power point tracking techniques," IEEE Trans. Energy Convers., vol. 22, no. 2, pp. 439-449, Jun. 2007.

[19] H. S.-H. Chung, K. K. Tse, S. Y. R. Hui, C. M. Mok, and M. T. Ho, "A novel maximum power point tracking technique for solar panels using a SEPIC or Cuk converter," IEEE Trans. Power Electron., vol. 18, no. 3, pp. 717-724, May 2003.

[20] W. Xiao, M. G. J. Lind, W. G. Dunford, and A. Capel, "Real-time identification of optimal operating points in photovoltaic power systems," IEEE Trans. Ind. Electron., vol. 53, no. 4, pp. 1017-1026, Jun. 2006.

[21] A. Garrigós, J. M. Blanes, J. A. Carrasco, and J. B. Ejea, "Real time estimation of photovoltaic modules characteristics and its application to maximum power point operation," Renew. Energy, vol. 32, no. 6, pp. 1059-1076, May 2007.

[22] J. M. Blanes, F. J. Toledo, S. Montero, and A. Garrigós, "In-site realtime photovoltaic I-V curves and maximum power point estimator," IEEE Trans. Power Electron., vol. 28, no. 3, pp. 1234-1240, Mar. 2013.

[23] R. Pradhan and B. Subudhi, "Design and real-time implementation of a new auto-tuned adaptive MPPT control for a photovoltaic system," Int. J. Electr. Power Energy Syst., vol. 64, pp. 792-803, Jan. 2015.

[24] F.-S. Pai, R.-M. Chao, S. H. Ko, and T.-S. Lee, "Performance evaluation of parabolic prediction to maximum power point tracking for PV Array," IEEE Trans. Sustain. Energy, vol. 2, no. 1, pp. 60-68, Jan. 2011.

[25] T. Ma, H. Yang, and L. Lu, "Development of a model to simulate the performance characteristics of crystalline silicon photovoltaic modules/strings/arrays,” Sol. Energy, vol. 100, pp. 31-41, Feb. 2014. E. I. Batzelis and S. A. Papathanassiou, "A method for the analytical extraction of the single-diode PV model parameters," IEEE Trans. Sustain. Energy, vol. 7, no. 2, pp. 504-512, Apr. 2016.

[27] E. I. Batzelis, G. E. Kampitsis, S. A. Papathanassiou, and S. N. Manias, "Direct MPP calculation in terms of the single-diode PV model parameters," IEEE Trans. Energy Convers., vol. 30, no. 1, pp. 226-236, Mar. 2015.

[28] G. Farivar, B. Asaei, and S. Mehrnami, "An analytical solution for tracking photovoltaic module MPP," IEEE J. Photovoltaics, vol. 3, no. 3, pp. 1053-1061, Jul. 2013.

[29] A. Kuperman, "Comments on 'An analytical solution for tracking photovoltaic module MPP," IEEE J. Photovoltaics, vol. 4, no. 2, pp. 734-735, Mar. 2014.
[30] A. Laudani, F. Riganti Fulginei, and A. Salvini, "High performing extraction procedure for the one-diode model of a photovoltaic panel from experimental I-V curves by using reduced forms," Sol. Energy, vol. 103, pp. 316-326, May 2014. http://en.wikipedia.org/wiki/Least_squares. "Levenberg-Marquardt algorithm." [Online]. Available: https://en.wikipedia.org/wiki/Levenberg-Marquardt_algorithm.

[33] J. C. H. Phang, D. S. H. Chan, and J. R. Phillips, "Accurate analytical method for the extraction of solar cell model paramaters," Electron. Lett., vol. 20, no. 10, pp. 406-408, Jan. 1984.

[34] A. Skoczek, T. Sample, and E. D. Dunlop, "The results of performance measurements of field-aged crystalline silicon photovoltaic modules," Prog. Photovolt.: Res. Appl., vol. 17, no. 4, pp. 227-240, Jun. 2009.

[35] W. Xiao, W. G. Dunford, P. R. Palmer, and A. Capel, "Regulation of photovoltaic voltage," IEEE Trans. Ind. Electron., vol. 54, no. 3, pp. 1365-1374, Jun. 2007.

[36] G. E. Kampitsis, A. P. Tsoumanis, K. C. Gallos, S. A. Papathanassiou, and S. N. Manias, "Experimental investigation of the response of different PLL algorithms to grid disturbances," Mater. Sci. Forum, vol. 856, pp. 291-296, Feb. 2016.

[37] R. H. Macmillan, An Introduction to the Theory of Control in Mechanical Engineering. Cambridge University Press, 1955.

[38] J. J. D’Azzo, C. H. Houpis, and S. N. Sheldon, Linear Control System Analysis and Design: Fifth Edition, Revised and Expanded. Marcel Dekker, 2003.

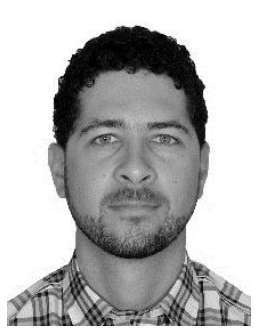

Dr. Efstratios I. Batzelis (S'14-M'17) received the Diploma in electronic \& computer engineering from Technical University of Crete (TUC) in 2009, the M.Sc. degree on energy production \& management from National Technical University of Athens (NTUA) in 2012, and the Ph.D. degree in electrical engineering from the same university in 2016 . He is currently a Research Associate (Postdoctoral Researcher) in Imperial College London.

His current research interests include renewable energy technologies and distributed generation, especially photovoltaics, inverter and power system control. This work was carried out during his $\mathrm{PhD}$ studies at NTUA.

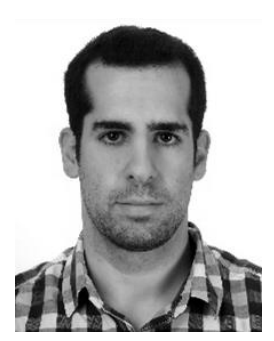

Dr. Georgios E. Kampitsis (S'12-M'17) received his Diploma and Ph.D. degree in electrical and computer engineering from the National Technical University of Athens (NTUA) in 2011 and 2016, respectively.

His research interests include development and control of high switching frequency, high efficiency power converters, based on wide band gap (WBG) semiconductor devices, for renewable energy sources (RES) and inductive power transfer systems (IPTS) applications.

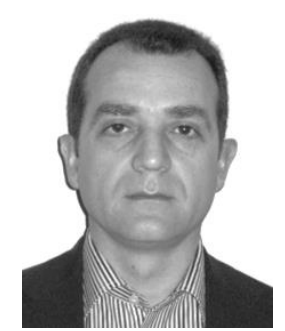

Prof. Stavros A. Papathanassiou (S'93-M'98SM'10) received the Diploma degree in Electrical Engineering and the Ph.D. degree from the National Technical University of Athens (NTUA), Athens, Greece, in 1991 and 1997, respectively.

He was with the Distribution Division, Public Power Corporation of Greece, engaged in power quality and distributed generation (DG) studies. In 2002, he joined the Electric Power Division, NTUA, where he is currently an Associate Professor. From 2009 to 2012, he was a Member of the Board of the Hellenic Transmission System Operator. His research interests are in the field of renewable energy sources (RES) and DG, including wind turbine and PV technology, storage applications and integration of DG to the grid. 